\title{
Rationalisation of the Fibonacci Charge Pump
}

\author{
David Matoušek \\ Department of Electrical Engineering \\ University of Pardubice \\ Pardubice, Czech Republic \\ david.matousek@upce.cz
}

\author{
Bohumil Brtník \\ Department of Electrical Engineering \\ University of Pardubice \\ Pardubice, Czech Republic \\ bohumil.brtnik@upce.cz
}

\begin{abstract}
This paper focuses on the practical aspects of the realisation the Fibonacci charge pump (FCP). The main attention is dedicated to the study of the influence of clock frequency and the capacitance of the used capacitor to key parameters of proposed FCP. This studying is performed by measurement of four specimens of FCP with different values of capacitance and clocking frequency. The rationalisation increases the efficiency to $85 \%$ approximately (for $V_{I N}=3 \mathrm{~V}$, Vout $=34.3 \mathrm{~V}$, Iout $=1 \mathrm{~mA}$ ). The results of this work allow rational selection of capacitance in relation to requested parameters of the designed charge pump.
\end{abstract}

Keywords-Fibonacci charge pump; rationalisation; efficiency; rise time; ripple voltage.

\section{INTRODUCTION}

Charge pumps are alternative to classic DC/DC converters that produce a voltage higher than supply voltage or a voltage of opposite polarity to the input. Charge pumps are used for low power applications in a range from microwatts to milliwatts, especially. These DC/DC converters fully eliminate the necessity of usage of inductors or transformers.

A standard variant of a charge pump is Dickson charge pump (DCP) [1], [2]. The Dickson charge pump is efficient and easy to integrate, but it has a relatively low voltage gain. In an ideal case, the voltage gain of each stage is the same as an amplitude of the used clock. Thus, the Dickson charge pump is useful only for a relatively low output to input voltage ratio. The no-load output voltage is calculated as [1]:

$$
V_{O}=V_{I N}+N \cdot\left(V_{\phi}-V_{D}\right)-V_{D},
$$

where $V_{O}$ is the no-load output voltage, $V_{I N}$ is the input voltage, $N$ is the number of stages, $V_{\phi}$ is the amplitude of clock, $V_{D}$ is the diode forward drop.

A variant of a charge pump with a higher voltage gain is a Fibonacci charge pump (FCP) [3], [4]. A principal schematic diagram of the FCP is shown in Fig. 1.

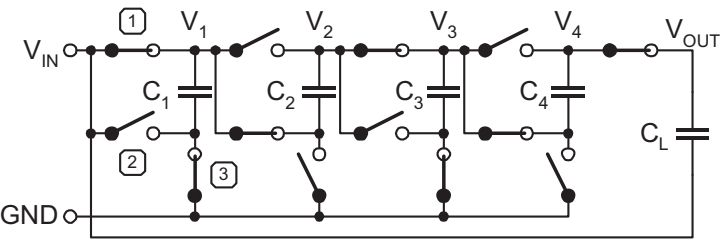

Figure 1. Principal schematic diagram of the 4-stage FCP.
The voltage gain of the FCP is gradually increased over pump stages. The voltage gain of the stage is defined as a Fibonacci number (the Fibonacci sequence is: $1,1,2,3,5,8, \ldots)$. Thus, the 4-stage FCP produces the no-load output voltage $8 \cdot V_{\text {IN }}$. Generally, the no-load output voltage of the FCP is:

$$
V_{O}=V_{I N}+V_{I N} \cdot \sum_{n=1}^{N} F_{n},
$$

where $V_{O}$ is the no-load output voltage, $V_{I N}$ is the input voltage, $N$ is the number of stages, $F_{n}$ is the Fibonacci number of the $\mathrm{nth}$ order $\left(F_{1}=1, F_{2}=1\right.$, for $\mathrm{n} \geq 3$ : $\left.F_{n}=F_{n-1}+F_{n-2}\right)$.

The FCP circuit is more complex than a Dickson charge pump circuit solution. Furthermore, the FCP circuit has a higher sensitivity for on-chip parasitic than Dickson charge pump circuit solution. Thus, the FCP concept is especially attractive to the pump realized by discrete components [4], [5], [6].

\section{FIBONACCI CHARGE PUMP REALISATION}

The realisation of the FCP was solved in the previous period [6], see Fig. 2. The reference design was based on these charge pump specifications:

- power supply voltage $\mathrm{V}_{\mathrm{IN}}=3 \mathrm{~V}$,

- the minimal steady-state output voltage $\mathrm{V}_{\text {OUT }}=30 \mathrm{~V}$ at the output current IOUT $=1 \mathrm{~mA}$,

- the maximal ripple voltage of the output $\mathrm{V}_{\mathrm{R}}=15 \mathrm{mV}$ (peak-to-peak),

- the maximal rise time of the output $t_{R}=65 \mathrm{~ms}$.

The result of the design procedure [6] leads to the identification of values of capacitance of the transfer and load capacitors and types of active elements, see Table I.

TABLE I. Result DEVICE PARAMETERS

\begin{tabular}{|l|l|}
\hline Parameter & Value or device \\
\hline $\begin{array}{l}\text { Load capacitance } \\
\text { and transfer capacitance }\end{array}$ & $\mathrm{C}=\mathrm{C}_{\mathrm{L}}=\mathrm{C}_{\mathrm{T}}=2.2 \mu \mathrm{F}$ \\
\hline Clock frequency & $\mathrm{f}=33 \mathrm{kHz}$ \\
\hline NMOS transistor & $\begin{array}{l}2 \mathrm{~N} 7002 \\
\left(\mathrm{~V}_{\mathrm{DSS}}=60 \mathrm{~V}, \mathrm{~V}_{\mathrm{GS}(\mathrm{th})}=2.1 \mathrm{~V}\right)\end{array}$ \\
\hline PMOS transistor & $\begin{array}{l}\mathrm{BSS} 84 \\
\left(\mathrm{~V}_{\mathrm{DSS}}=-50 \mathrm{~V}, \mathrm{~V}_{\mathrm{GS}(\mathrm{th})}=-1.7 \mathrm{~V}\right)\end{array}$ \\
\hline Schottky diode & $\begin{array}{l}\text { PMEG4010BEA } \\
\left(\mathrm{V}_{\mathrm{RRM}}=40 \mathrm{~V}, \mathrm{~V}_{\mathrm{D}}=0.155 \mathrm{~V}\right)\end{array}$ \\
\hline
\end{tabular}




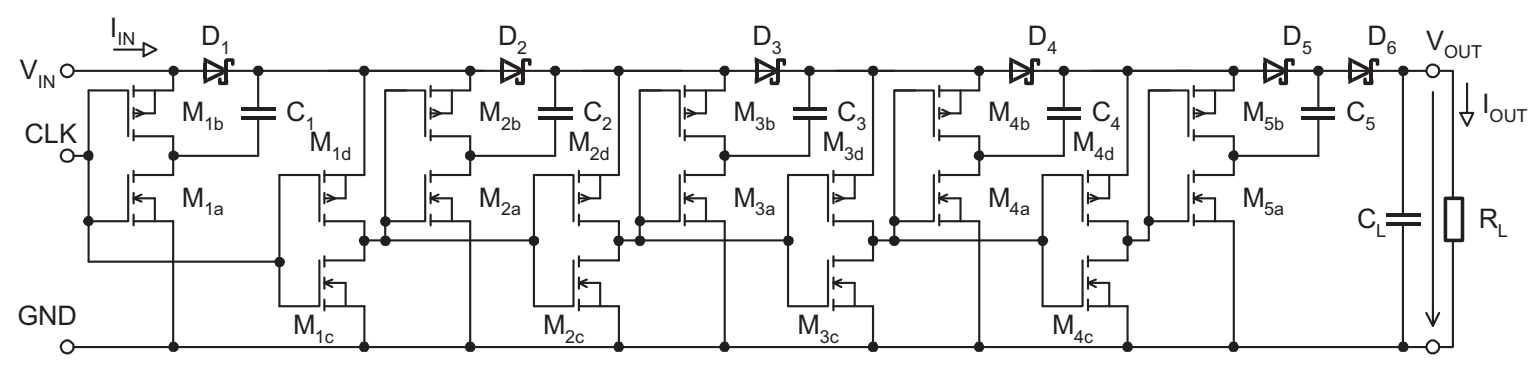

Figure 2. Schematic diagram of the 5-stage FCP.

The proposed FCP circuit solution according to Fig. 2 was successfully verified by simulation in LTspice XVII. Results from simulations confirm the functionality of this design. The output no-load voltage was $\mathrm{V}_{\mathrm{O}}=35.00 \mathrm{~V}$ and the output voltage at a defined load current $\mathrm{I}_{\text {OUT }}=1 \mathrm{~mA}$ was $\mathrm{V}_{\text {OUT }}=33.14 \mathrm{~V}$. The rise time and the ripple voltage had values $t_{\mathrm{R}}=17.37 \mathrm{~mA}$ and $\mathrm{V}_{\mathrm{R}}=7.24 \mathrm{mV}$ (peak-to-peak) at defined load current IouT $=1 \mathrm{~mA}$.

The FCP circuit solution (compare Fig. 1 and Fig. 2) is based on using transistors and diodes as switches. Switch \#1 (see Fig. 1) is realised as Schottky diode $\mathrm{D}_{\mathrm{x}}$ ( $\mathrm{x}$ is an ordinal node number). Switch \#2 (see Fig. 1) is realised as PMOS transistor $M_{x b}$ that works as a high-side switch. Switch \#3 (see Fig. 1) is realised as NMOS transistor $\mathrm{M}_{\mathrm{xa}}$ that works as a low-side switch.

Auxiliary transistors $\mathrm{M}_{\mathrm{xc}}, \mathrm{M}_{\mathrm{xd}}$ realise inverter that generates inverted and voltage shifted clock signal for the next stage of the charge pump. The presence of this inverter is essential for a regular function of the next stage and the whole charge pump. But, the auxiliary inverter implies the fact that a shoot-through current arises. Thus, the capacitor connected to the appropriate node is discharged by this shoot-through current. Therefore, the power consumption is increased, and the output voltage and the efficiency of the charge pump are decreased. This problem may be solved by a more complex circuit architecture that uses the inverter extended about an auxiliary current limiter.

The second problem of the implemented auxiliary inverter is a propagation delay. The propagation delay of inverters is gradually increased from the input to the output of the charge pump. The timing discrepancy between the stages may cause a loss of a charge. Thus, the clock frequency must be relatively low.

\section{Study OF Clock FreQuency InfLuENCE TO PARAMETERS OF THE FCP}

The question of enough value of the clock period is very important because strongly limits the key charge pump parameters as the efficiency and the output voltage on the one side and the secondary parameters as the rise time and ripple voltage on the other side.

The capacitance of the load capacitor $C_{L}$ and the clock frequency $f$ product marked as CFP must be a constant value for actual design because the ripple voltage [1] $V_{R}$ depends on this product (4).

$$
\begin{gathered}
C F P=C_{L} \cdot f, \\
V_{R}=\frac{I_{O U T}}{C_{L} \cdot f}=\frac{I_{O U T}}{C F P} .
\end{gathered}
$$

where $I_{\text {OUT }}$ is the output current, other parameters are explained above.

The rise time parameter $t_{R}$ is limited only by the value of capacitance $C_{L}[2]$.

$$
t_{R}=\frac{V_{O U T}}{I_{O U T}} \cdot C_{L} .
$$

The study of clock frequency influence to parameters of charge pump were executed for values: $\mathrm{C}_{1}=1 \mu \mathrm{F} \quad\left(\mathrm{f}_{1}=72.6 \mathrm{kHz}\right), \mathrm{C}_{2}=2.2 \mu \mathrm{F} \quad\left(\mathrm{f}_{2}=33 \mathrm{kHz}\right)$, $\mathrm{C}_{3}=4.7 \mu \mathrm{F} \quad\left(\mathrm{f}_{1}=15.4 \mathrm{kHz}\right) \quad$ and $\quad \mathrm{C}_{4}=10 \mu \mathrm{F}$ $\left(\mathrm{f}_{1}=7.26 \mathrm{kHz}\right)$. The CFP parameter is about 0.0726 for the values (3). Theoretically assumed results from LTspice XVII simulator is depicted on Fig. 3.

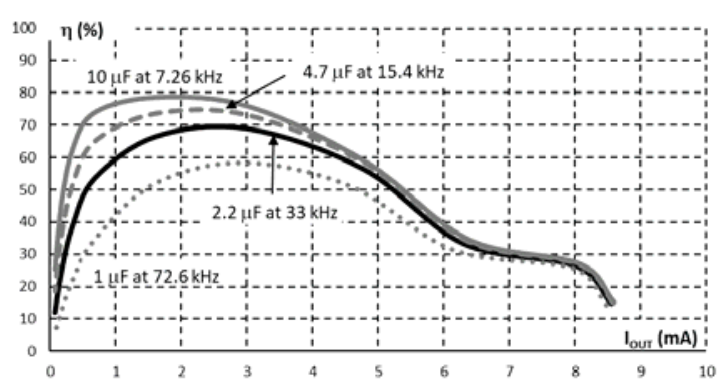

Figure 3. Efficiency vs. output current for various values of capacitance of capacitors calculated by simulation [6].

Four variants of FCP specimens with capacitances $\mathrm{C}_{1}=1 \mu \mathrm{F}, \mathrm{C}_{2}=2.2 \mu \mathrm{F}, \mathrm{C}_{3}=4.7 \mu \mathrm{F}$ and $\mathrm{C}_{4}=10 \mu \mathrm{F}$ were realised as double-sided PCBs, see Fig. 4.

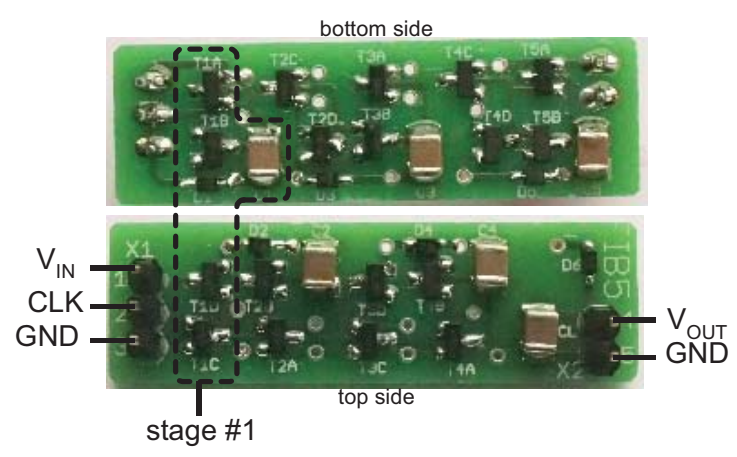

Figure 4. Photography of FCP specimen \#2 $(12 \times 40 \mathrm{~mm})$. 
The key parameters of all specimens were measured by the circuit according to Fig. 5 .

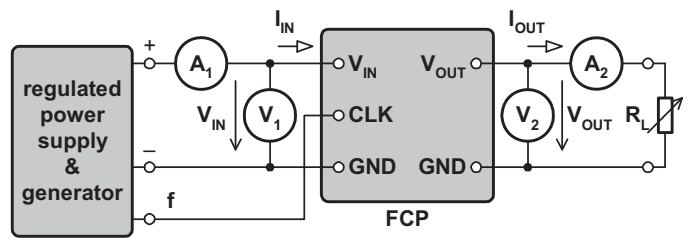

Figure 5. The circuit for $\mathrm{V}_{\text {Out }}$ and $\eta$ measuring.

The ammeters $A_{1}, A_{2}$ and voltmeters $V_{1}, V_{2}$ measure the input and the output currents and voltages. All ammeters measure the average value of a current [7], and the input and output voltages in the steady-state are close to DC. Thus, the calculation of the input and output power and the efficiency can be simplified to form (6) [8].

$$
\eta=\frac{P_{O U T}}{P_{I N}} \cdot 100 \%=\frac{V_{O U T} \cdot I_{O U T}}{V_{I N} \cdot I_{I N}} \cdot 100 \% .
$$

The precise measurement requires that the input voltage $V_{\text {IN }}$ has the fixed value $3 \mathrm{~V}$. Thus, a voltage drop of the ammeter $A_{1}$ must be compensated by a voltage regulator. But, the clock amplitude must have the same value as the input voltage. Thus, the clock amplitude must be changed automatically with a change of the input voltage.

The measurement was simplified by a circuit according to Fig. 6. This circuit contains the regulated power source based on $\mathrm{IC}_{1}$ (LM317T) and the frequency generator based on microcontroller $\mathrm{IC}_{2}$ (ATtiny2313). The voltage regulator produces an input voltage for FCP that is regulated by potentiometer P. The same voltage is used for powering of the microcontroller. Thus, the microcontroller produces clock signals with the same amplitude as the regulated voltage. The microcontroller program produces two different frequencies $f_{1}$ and $f_{2}$. These frequencies are defined by the crystal resonator $\mathrm{X}$ and the combination of DIP switches SW according to (7).

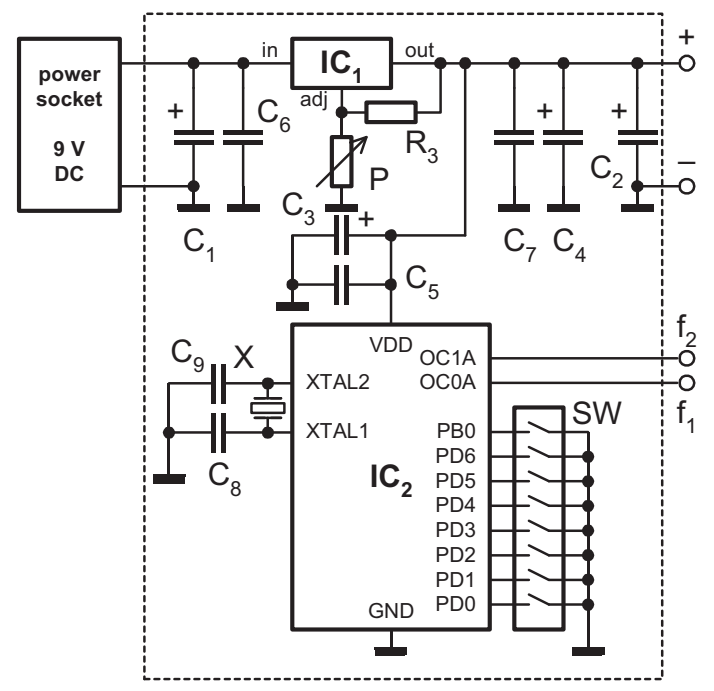

Figure 6. Schematic diagram of regulator \& generator.

$$
f_{1}=\frac{4 \mathrm{MHz}}{\mathrm{SW}+1}, \quad f_{2}=\frac{500 \mathrm{kHz}}{\mathrm{SW}+1}
$$

where $f_{1}, f_{2}$ are output frequencies of the generator, $S W$ is the combination of DIP switches in the range from 0 to 255 .

The CFP parameter of each specimen was calculated by the formula (3). The original values $\mathrm{C}=2.2 \mu \mathrm{F}$ and $\mathrm{f}=33 \mathrm{kHz}$ define $\mathrm{CFP}=0.0726$. We calculate the frequency value for other values of capacitance by the same value of the CFP as:

- $\mathrm{C}=1 \mu \mathrm{F}$ gives $\mathrm{f}=72.60 \mathrm{kHz}$,

- $\mathrm{C}=4.7 \mu \mathrm{F}$ gives $\mathrm{f}=15.45 \mathrm{kHz}$,

- $\mathrm{C}=10 \mu \mathrm{F}$ gives $\mathrm{f}=7.26 \mathrm{kHz}$.

This frequency value $f_{B}$ is used as a base value for calculation other frequencies. The minimal frequency is calculated as $f_{B} / 2$ and the maximal frequency is calculated as $2 \cdot \mathrm{f}_{\mathrm{B}}$. Last two values of frequency are calculated as $\mathrm{f}_{\mathrm{B}} / 1.5$ and $1.5 \cdot \mathrm{f}_{\mathrm{B}}$. By this method, we got five values of frequency for each specimen. Practically generable value of the frequency is limited by the resolution of the microcontroller frequency generator (7). The individual values of frequency in kilo-Hertz for four specimens are:

- $\quad \# 1(1 \mu \mathrm{F}): 36.36,48.20,72.73,108.11,148.15$,

- $\quad$ \#2 $(2.2 \mu \mathrm{F}): 16.53,22.22,33.06,50.00,66.67$,

- $\quad \# 3(4.7 \mu \mathrm{F}): 7.81,10.42,15.63,23.81,31.25$,

- $\quad \# 4(10 \mu \mathrm{F}): 3.62,4.85,7.25,10.87,14.71$.

All FCP specimen variants were measured on five values of the clock frequency according to Table II. The measured efficiency as the main parameter is documented by Fig. 7 to Fig. 10. Other results are listed in Table II.

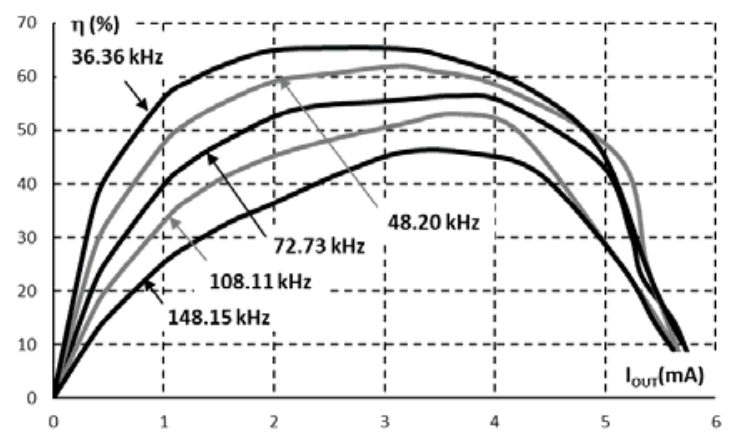

Figure 7. Efficiency vs. output current for various frequencies, variant $\# 1: \mathrm{C}=1 \mu \mathrm{F}$.

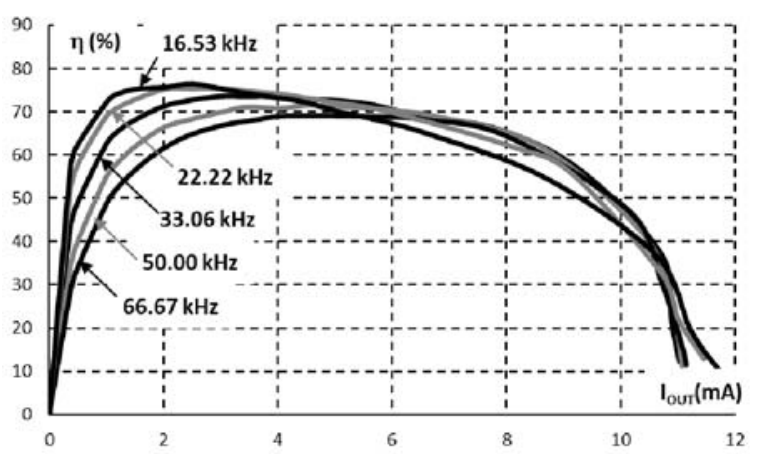

Figure 8. Efficiency vs. output current for various frequencies, variant $\# 2$ : $\mathrm{C}=2.2 \mu \mathrm{F}$. 


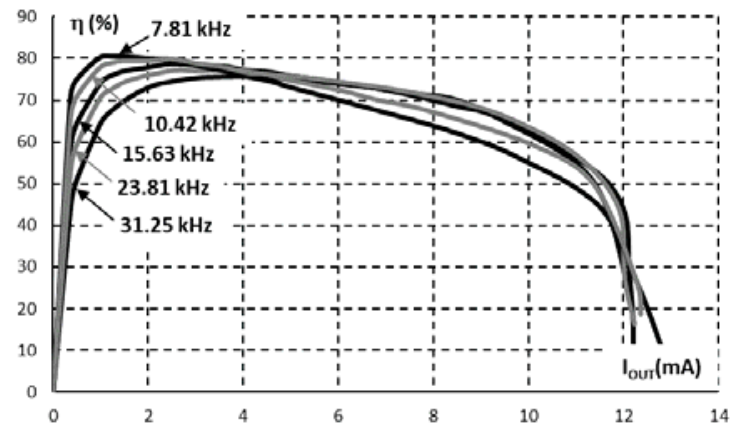

Figure 9. Efficiency vs. output current for various frequencies, variant \#3: $\mathrm{C}=4.7 \mu \mathrm{F}$.

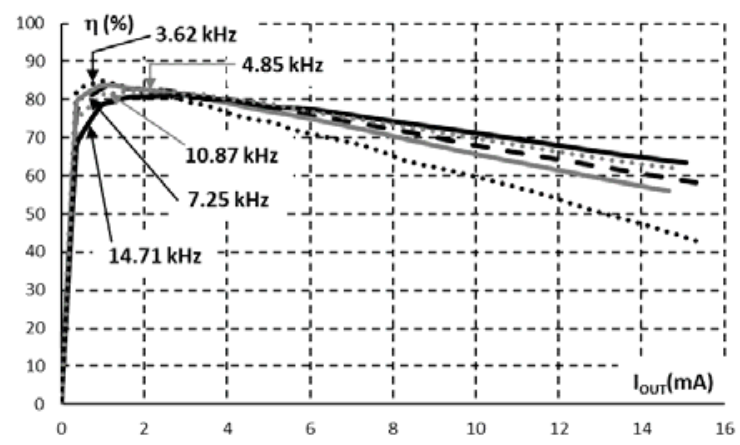

Figure 10. Efficiency vs. output current for various frequencies, variant \#4: $\mathrm{C}=10 \mu \mathrm{F}$.

The first variant (Fig. 7) has a strong frequency dependency, the efficiency varies in the range from $25.4 \%$ to $56 \%$ for the output current $1 \mathrm{~mA}$. The second (Fig. 8) and the third variant (Fig. 9) are very similar. Both characteristics are flattened, thus the efficiency is close to constant value. The fourth variant (Fig. 10) is very similar to the previous two variants, too. But, in the measured range, variant \#4 disposes of enough power reserve.

The rise time $t_{R}$ of the output voltage was measured by the schematic diagram in Fig. 11. Firstly, the switch $\mathrm{S}$ was closed and after then, the input voltage and output current were set to values $\mathrm{V}_{\mathrm{IN}}=3 \mathrm{~V}, \quad \mathrm{I}_{\mathrm{OUT}}=1 \mathrm{~mA}$ in steady-state. This oscilloscope was used for measuring the ripple voltage $\mathrm{V}_{\mathrm{R}}$ on the output. Secondly, the oscilloscope was configured for triggering by channel 1 and for a single shot and after then, the switch $\mathrm{S}$ was opened. The oscilloscope recorded the ramp of the output voltage after closing the switch $\mathrm{S}$.

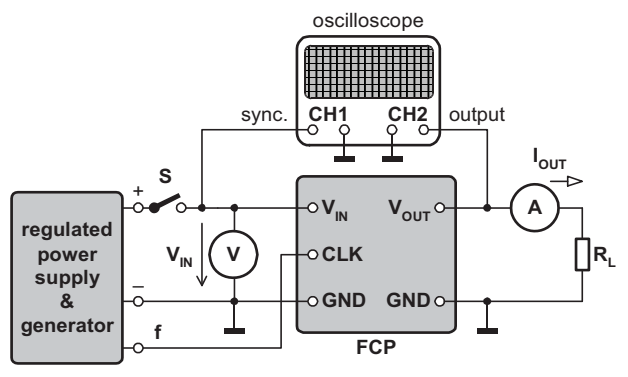

Figure 11. The circuit for $t_{R}$ and $V_{R}$ measuring.

The measured results of all variants for various frequencies are listed in Table II. The bold letters indicate sub-tables, the strikeout letters indicate values that miss charge pump specifications.
TABLE II. MEASURED RESUlts $\left(\mathrm{V}_{\mathrm{IN}}=3 \mathrm{~V}, \mathrm{I}_{\mathrm{OUT}}=1 \mathrm{~mA}\right)$

\begin{tabular}{|c|c|c|c|c|c|}
\hline \multirow{2}{*}{$\begin{array}{c}\begin{array}{c}\text { Variant/ } \\
\text { parameter }\end{array} \\
\# 1\end{array}$} & \multicolumn{5}{|c|}{ Clock frequency $(\mathrm{kHz})$} \\
\hline & 148.15 & 108.11 & 72.73 & 48.20 & 33.36 \\
\hline $\mathrm{V}_{\text {OUT }}(\mathrm{V})$ & 31.0 & 31.9 & 32.5 & 32.7 & 32.8 \\
\hline$\eta(\%)$ & 25.4 & 34.5 & 39.8 & 47.5 & 56.0 \\
\hline $\mathrm{t}_{\mathrm{R}}(\mathrm{ms})$ & 18.3 & 18.1 & 17.7 & 17.3 & 16.7 \\
\hline $\mathrm{V}_{\mathrm{R}}(\mathrm{mV})$ & 5.2 & 5.4 & 6.4 & 10.8 & 26.4 \\
\hline$\# 2$ & 66.67 & 50.00 & 33.60 & 22.22 & 16.53 \\
\hline $\mathrm{V}_{\text {OUT }}(\mathrm{V})$ & 33.7 & 33.9 & 34.0 & 34.0 & 33.9 \\
\hline$\eta(\%)$ & 49.1 & 55.1 & 62.6 & 68.7 & 72.6 \\
\hline $\mathrm{t}_{\mathrm{R}}(\mathrm{ms})$ & 19.1 & 18.1 & 18.3 & 18.4 & 18.7 \\
\hline $\mathrm{V}_{\mathrm{R}}(\mathrm{mV})$ & 6.7 & 7.7 & 11.0 & 12.4 & 15.2 \\
\hline$\# 3$ & 31.25 & 23.81 & 15.63 & 10.42 & 7.81 \\
\hline $\mathrm{V}_{\text {OUT }}(\mathrm{V})$ & 34.3 & 34.3 & 34.3 & 34.4 & 34.3 \\
\hline$\eta(\%)$ & 64.0 & 70.6 & 74.4 & 77.8 & 79.9 \\
\hline $\mathrm{t}_{\mathrm{R}}(\mathrm{ms})$ & 29.6 & 30.4 & 32.0 & 32.2 & 32.6 \\
\hline $\mathrm{V}_{\mathrm{R}}(\mathrm{mV})$ & 10.2 & 11.4 & 18.6 & 26.6 & 37.6 \\
\hline$\# 4$ & 14.71 & 10.87 & 7.25 & 4.85 & 3.62 \\
\hline $\mathrm{V}_{\text {OUT }}(\mathrm{V})$ & 34.5 & 34.4 & 34.4 & 34.5 & 34.3 \\
\hline$\eta(\%)$ & 78.1 & 81.4 & 83.1 & 83.4 & 84.7 \\
\hline $\mathrm{t}_{\mathrm{R}}(\mathrm{ms})$ & 48.2 & 48.4 & 51.0 & 55.8 & 57.8 \\
\hline $\mathrm{V}_{\mathrm{R}}(\mathrm{mV})$ & 8.6 & 11.6 & 18.8 & 29.2 & 40.4 \\
\hline
\end{tabular}

\section{CONCLUSIONS}

Generally, the efficiency increases as the working capacitance increases and the clocking frequency decreases. Therefore, the maximal efficiency is $\eta=84.7 \%$ when $\mathrm{C}=10 \mu \mathrm{F}$ and $\mathrm{f}=3.62 \mathrm{kHz}$. But, the ripple voltage on output $\left(\mathrm{V}_{\mathrm{R}}=40.4 \mathrm{mV}\right)$ exceeds maximal acceptable value $15 \mathrm{mV}$.

Table II gives the possibility to a rationalization of charge pump design in relation to the efficiency, rise time, ripple voltage, and capacitors cost.

\section{REFERENCES}

[1] J. F. Dickson, "On-Chip high-voltage generation in NMOS integrated circuits using an improved voltage multiplier technique", IEEE Journal of Solid-State Circuits, vol. 11, No. 3, pp. 374-378, 1976.

[2] F. Pan, and T. Samaddar, Charge pump circuit design, McGraw-Hill, New York, 2006.

[3] F. Ueno, T. Inoue, I. Oota, and I. Harada I., "Emergency power supply for small computer systems", In proceedings of IEEE International Conference Circuits and System, Singapore, 1991, pp. 1065-1068.

[4] Tanzawa, T. (2016). Innovation of Switched-Capacitor Voltage Multiplier, Part 1: A brief history. IEEE Solid-State Circuits Magazine, pp. 51-59, Winter 2016.

[5] Y. Allasasmeh, and S. Gregori, "A Performance Comparison of Dickson and Fibonacci Charge Pumps", In proceedings of European Conference of Circuit Theory and Design, 2009, pp. 599-602.

[6] D. Matousek, J. Hospodka, and O. Subrt, "New Discrete Fibonacci Charge Pump Design, Evaluation and Measurement," MEASUREMENT SCIENCE REVIEW, vol. 17, No. 3, pp. 100-107, 2017.

[7] S. Tumanski, Principles of Electrical Measurement, CRC Press, New York, 2006.

[8] I. Mayergoyz, and W. Lawson, Basic Electric Circuit Theory, 2nd Edition, Academic Press, Cambridge, 2012. 